\title{
The Effectiveness of Negotiations over International River Claims
}

\author{
Marit Brochmann \\ Department of Political Science \\ University of Oslo \\ P. O. Box 1097, Blindern \\ Oslo 0317, Norway \\ and \\ Centre for the Study of Civil War (CSCW), PRIO \\ marit.brochmann@stv.uio.no \\ Paul R. Hensel \\ Department of Political Science \\ University of North Texas \\ P.O. Box 305340 \\ Denton, TX 76203-5017 \\ phensel@unt.edu
}

Draft version for presentation at ISA conference;

please contact the authors for latest version before citing.

Rising demands for fresh water in already water-scarce areas have created a common perception that "water wars" are going to occur frequently in coming years, although evidence suggests that water is at least as important a source of cooperation as of conflict. This paper follows up on recent research in which we have found that river disagreements are more likely to lead to both militarized conflict and peaceful negotiations when water demands and water scarcity are greatest, but that river treaties have generally prevented militarization while increasing negotiations. Here we examine the effectiveness of these negotiations, in order to determine whether these factors that promote negotiation onset tend to lead to successful negotiations (as seems plausible for river treaties) or whether the negotiations that result more typically end in failure (as seems plausible for negotiations prompted by serious armed conflict and international pressure). Empirical analysis suggests that river negotiations are most likely to succeed when the river is more salient, when the specific problem being discussed is already operational, and when the adversaries share closer overall relations, and less likely when there is a recent history of failed negotiations over the same river.

Paper presented at the Annual Meeting of the International Studies Association, New York, 16 February 2009. All opinions and recommendations expressed herein are those of the authors. 


\section{The Effectiveness of Negotiations over International River Claims}

Shared rivers form an important context for relations between neighboring states. Research has identified a number of forms of interaction that are affected by sharing rivers, ranging from river treaties or institutions to general patterns of interstate conflict and cooperation and even armed conflict over the use of the rivers. Research also suggests that patterns of conflict and cooperation in international basins may be interrelated, with changes in one being followed quickly by changes in the other.

In order to improve the management of international rivers, we believe it is crucial to increase our understanding of how to push interactions in a more cooperative direction. This is particularly important where interactions over a shared river have already led states to the point of diplomatic disagreement over the river. If nothing is done to manage or resolve such disagreements, the relationship could quickly begin a spiral of increasing conflict and decreasing cooperation, leaving each riparian worse off than they had been before the disagreement began. If such disagreements can be managed and then resolved, though, agreement over the use of the river can lead to mutual benefits for each riparian. In several recent papers we have begun to investigate the conditions under which states that share rivers are more likely to begin disagreements over the rivers, and to attempt to manage these disagreements through both militarized conflict and peaceful negotiations. The present paper follows up on these earlier works by investigating the conditions that influence the effectiveness of such peaceful negotiations over river disagreements.

We begin by presenting a simple model of interaction over rivers that emphasizes details of the river itself, the level of water scarcity and water demands in the river's basin, and the riparian states as influences on both the onset and success of negotiations. We use a Heckman model to evaluate this model while taking into account the possibility of selection effects in the negotiation process. Our results suggest that even if there are no apparent selection effects in place, many of the same factors affect the success of negotiations and the beginning of negotiations. Successful negotiations are most likely when the river in question is highly salient or if there is a generally cooperative relationship between the two countries. On the other hand, negotiations are less likely to succeed when the negotiation is over future concerns rather than 
current, or when negotiations over the river have recently failed. We conclude by discussing some of the implications of these preliminary results.

\section{Theory}

States can be understood as rational egoists that pursue their own interests in an anarchic state system. In such a system, states often find their interests colliding with those of other states, creating the opportunity for both conflictual and cooperative interactions as the states seek to resolve the matter. Fearon (1995: 380ff) argues that in any interaction between states, there will always exist a peaceful solution that both sides would prefer over a violent conflict; war is a costly event, and both parties would be better off if an issue could be resolved without turning violent. But factors such as private information and incentives to misrepresent information can limit the apparent bargaining range and lead to conflicts instead, even with rational leaders in place. Other scholars suggest that states can nonetheless cooperate for either of two reasons: (1) they expect to gain more from collective action than unitary action, or (2) they seek to prevent a pending threat from leading to a costly conflict (e.g. Stein 1989; Zartman 1989; Keohane and Ostrom 1994; Keohane 2002).

We seek to understand the conditions under which states that share a river are most likely to settle their differences through peaceful negotiations. Shared rivers offer access to fresh water, a resource that is already scarce in many parts of the world and is becoming increasingly scarce as current supplies are overused or polluted. Besides the obvious use as drinking water for human consumption, river water can be used to irrigate crops or generate hydroelectric power, and the river itself might be used for such purposes as commercial navigation or fishing. Yet a finite amount of water traverses any given river system, and many actions by one state -ranging from diversion for irrigation or for consumption by distant communities or damming for hydroelectric power generation to (intentional or unintentional) pollution by the state's industries -- may affect the amount or quality of water available to other states in the basin. Many rivers are also shared by more than two states, complicating river management because of the potentially large number of states whose interests must be taken into account. Indeed, according to Elhance (2000), the complexity of hydropolitics makes it one of the most challenging arenas of interstate interaction and negotiation in some regions of the world. 
Previous studies have investigated the extent to which shared water resources push states in conflictual or cooperative directions, and we have examined when states tend to enter into negotiations over their shared water resources (Brochmann and Hensel 2009). Here we go one step further and ask under what conditions these negotiations tend to be successful, that means, end in a treaty or resolve the disagreement over which the negotiations started. Next we present our theoretical model ending in several hypotheses for testing.

\section{A Simple Model of Interaction over Rivers}

In several previous studies we have started from a basic conceptual model of states' interaction over a transboundary river. The model begins with two states that share an international river. One state -- the upstream state -- has access to the water resources of the river before they reach the downstream state, and may choose to take advantage of these resources for such purposes as human consumption, industry, irrigation, and damming for hydroelectric power generation. If it chooses to do so, there may be some effect on the quantity or quality of the river's water that reaches the downstream state, or even on the downstream state's ability to navigate the river.

If the downstream state believes that the upstream state's actions are having such an effect (or will have this effect in the future), it may respond by making explicit demands that the upstream state stop or modify its actions in such a way as to protect the downstream state's interests. If such demands are made, the two sides may choose from any number of actions to address the demands: the upstream state may decide to comply with the demands, the two states may attempt to settle the issue peacefully (whether through bilateral negotiations, talks with nonbinding third party assistance, or submission of the issue to a binding third party judgment), or either state may threaten or use military force to support its position.

In previous papers, we have used this basic model to study both the onset of militarized conflict over rivers (Hensel and Brochmann 2007) and negotiations over rivers (Brochmann and Hensel 2009). Following past work on international bargaining in general terms as well as international river management, we have focused on two broad groups of factors to try to understand how rivers will be managed: those related to the river (including conditions in the larger basin of which it is part as well as institutionalization in the form of river treaties) and those related to the riparian states (including the recent state of the relationship between them). 
In these earlier papers, the perceived importance of the river is important for both the origins and management of river claims. States are more likely to begin disagreements over rivers that are seen as more important -- whether measured by the length of the river or by water scarcity or demands in the river's basin. The stronger the downstream state, though, the less likely a claim is, as the upstream state is less likely to take actions that might threaten downstream interests and spawn a claim.

Once a claim has begun, river importance has an important influence in the onset of both militarized and peaceful efforts to manage or settle the claim. The more important the river (or the more salient the claim that is made over the river), the more likely that states are to become involved in militarized conflict over the claim -- but also more likely that they begin negotiations over the claim. The presence of existing treaties over the river tends to increase negotiations and decrease militarized conflict, while a more cooperative overall relationship between the riparians tends to increase the likelihood of negotiations.

Of course, the mere initiation of a round of peaceful negotiations is no guarantee for a success; the real key to long-term cooperation lies in the degree to which two states manage to engage in successful cooperation. Once negotiations begin, the process may take any number of directions -- potentially ending in an agreement that lays the groundwork for decades of cooperation over the river, or perhaps breaking down without agreement and poisoning relations for many years to come. The present paper investigates this process; if the two states attempt to resolve their disagreement over the river peacefully, how likely are they to be successful, and which factors help to determine the success of these attempts? As with our past work in this area, we focus on factors related to both the river and the riparian states to help answer this question. We now turn to hypotheses on each of these groups of factors.

\section{Hypotheses on River Details}

Our first set of hypotheses concerns the importance of the river itself in interaction between riparians. One must keep in mind that there is an important distinction between starting talks and reaching a successful agreement. We expect that some factors may have opposite effects on these two outcomes. In particular, factors like the salience (or importance) of a given river or the amount of recent armed conflict related to that river should increase the likelihood that states will begin negotiations over the river claim, as they note the greater urgency and the 
greater risk involved in leaving the conflict festering without a resolution. Yet while there may be greater urgency to seek a peaceful settlement in situations such as these, we should expect to see a lower likelihood that the negotiations will produce a successful solution. The reason is that the more important -- or more threatening -- the issue is, the more difficult it will be for leaders on either side to reach a mutually acceptable compromise outcome.

Bearing this in mind, the primary reason why states enter into negotiations to resolve their water issues is obviously the importance of water as a resource. Central to nearly all theorizing about shared rivers is the notion that water is essential to human livelihood. In order for state leaders to be willing to take action to secure access to or preserve a certain good it has to be considered to be of sufficient importance. This has typically been seen in the notion of water scarcity, as states can suffer from scarcity with respect to water for human consumption, agricultural uses, industry, or power generation; the ability to address these needs will affect a river's perceived importance. Access to sufficient supplies of water will always be essential, and where water is scarce or under heavy demand it is likely to constrain and put pressure on political leaders in negotiation processes. This may make agreements difficult to reach because neither state can afford to lose. Dinar (2008) argues along these lines that the main obstacle to fostering cooperation in international river basins is negotiating the terms of institutional arrangements that make lasting cooperation beneficial to all parties. Because fresh water is of such importance, he argues, strategic interaction is instrumental in understanding the formation of this cooperation with issue-linkage, reciprocity and side-payments as building blocks (2008: 16ff; see also Song and Whittington 2004). This is also similar to Keohane's argument that states will cooperate once they perceive that cooperation will be beneficial and that the absolute gains are more important than the relative gains in the negotiation process.

Further complicating matters in international river basins is the lack of widely accepted international law governing international water management. The closest to a joint legal doctrine for management of international rivers is the UN Convention for the Law of the NonNavigational Uses of International Watercourses, which was adopted by the UN General Assembly in 1997. Yet only 22 countries were party to the convention in one way or another a decade later, well below the 35 needed to bring the convention into force (Giordano and Wolf, 2003: 168; Internationalwaterlaw.org 2009). The Convention may offer guidance in negotiation processes but not enforce solutions. This means that states need to negotiate property rights and 
efficiency gains simultaneously (Dombrovsky 2007: 24). Although this makes negotiations complex it may also increase the chance of successful negotiations as different states may have different advantages in the negotiation process, mainly due to geography and capabilities.

Hypothesis 1: States are more likely to begin negotiations over a river claim, but these negotiations are less likely to be successful, if the river is considered to be more important.

A second consideration with respect to rivers is the nature of the grievance(s) being contested. Whether a given disagreement involves the quantity or quality of water reaching the downstream state or navigation rights, there would seem to be an important distinction between current problems that are already affecting the downstream state and pending problems that are seen as likely to affect it in the future. For example, there should be a difference between a dam project that is being planned or constructed (but not yet affecting the amount of water flowing across the border) and a similar project that is in operation and actively reducing the water flow. We expect that negotiations should be more likely to begin over pending issues that have not yet taken effect, but that the lack of current harm to the downstream state coupled with the hope of great future benefits for the upstream state should make the successful resolution of such negotiations less likely:

Hypothesis 2: States are more likely to begin negotiations over a river claim, but these negotiations are less likely to be successful, if the river claim only involves the challenger state's concerns about future usage of the river than if it involves concerns about the current usage of the river.

In addition to water availability, the river feature that first and foremost affects the interaction pattern between riparians is the geographical configuration of the river. Although Dinar (2008: 3) identifies fourteen different types of river configurations, we will here focus on the upstream/downstream relationship in general (meaning that a river has to run through at least parts of state A before it enters into state B). As outlined above, such a geographic configuration provides inherent asymmetries among riparians that favor the upstream state. As we have suggested elsewhere (Brochmann and Hensel 2009), such a configuration provides greater 
opportunity for the upstream state to take actions over the river that risk harming the interests of the downstream state. This should increase the risk that a river claim would begin (and, indeed, that other paper has found evidence to support this). It should also increase the likelihood of negotiations over the river once such a claim has begun, as the upstream state's actions create greater urgency for the downstream state to rectify the situation and protect its water-related interests. ${ }^{1}$

Hypothesis 3: States are more likely to begin negotiations over a river claim that involves a river that crosses the border from one state into the other than over claims involving rivers with other courses.

Our next hypothesis addresses the institutionalization of a river through existing treaties. To the extent that the use of the river is already governed by one or more treaties, negotiations over the river should be more likely to succeed, because there is already an agreed-upon starting point for negotiations. In contrast, where there are no treaties between the claimants over the river in question, negotiations should be more difficult because the two sides are starting from scratch; rather than converging around an existing framework that might be modified based on current needs, they need to establish an original framework for the first time.

Hypothesis 4: States are more likely to begin negotiations over a river claim, and these negotiations are more likely to be successful, when they share at least one relevant treaty over the river that addresses the substance of the claim.

\section{Hypotheses on Riparian State Details}

According to the simple model presented earlier, a downstream country has the "geographical power disadvantage" and is more likely to object to the use of water from the upstream state or initiate negotiations if it is more powerful. Even more so, we would expect that

\footnotetext{
${ }^{1}$ We do not provide an hypothesis for the impact of river course on negotiation success because the Heckman selection models that we employ in this paper require somewhat different lists of variables in the two stages of the model (in this case the onset and success of negotiations) in order to run accurately. We chose to omit river course from the second stage of the model for this purpose, because we had less reason to expect a systematic impact on negotiation success from this than for the other variables in the model.
} 
regardless of whether it is the upstream or downstream state that initiates a given claim in the first place, how it evolves depends mostly on the relative capabilities of the challenger, or the initiator state. This is because this is the state that is pursuing the claim and seeking to change the status quo on the river and a stronger challenger can put credible force behind a claim and force through both negotiations and agreements. We thus expect that negotiations are more likely to be initiated and more likely to be successful once begun if the challenger state is the most powerful.

As discussed earlier, we expect that rivers that cross the border from one state's territory to another's might be more dangerous, and thus more in need of negotiations. One way this situation could be overcome, though, would involve a downstream state that is more powerful than its upstream counterpart. Lowi $(1995,1999)$ among others argue that the interest of the hegemonic state in a basin is decisive for the nature of the interaction in the basin. Egypt's role in the Nile basin is an example of a downstream state that is able to dictate much in the basin due to its relative power. It is superior to the other riparian states, such that the latter are unlikely to engage in actions that could provoke a hostile response downstream (Lowi 1999). Side-payments and issue linkage are other mechanisms that can affect the bargaining range and make solutions more attractive to all parts. In addition to the actual items in the bargaining or negotiations, lasting cooperation depends on trust. Countries are more willing to cooperate if they see their relationship as long-term, with the resultant expectations about the other's behavior embodied in the well-known "shadow of the future" (Song and Whittington 2004). The more complex the cooperation is over time, the more likely it is that the political differences between the cooperative states diminish (Lowy 1995: 1), and this makes way for even more extensive cooperation and even spillovers to other issue areas. Complex interdependence ties different states together and the idea behind the peacekeeping effect of this is that the more tightly intertwined and interdependent the valued interaction amongst states, the greater the incentives for long-term cooperation in order to avoid disrupting these ties. A crucial point is the extent to which the actors feel that they are involved in a network of mutual interaction and that they feel they benefit from this (Keohane 2002: 54).

We consider relative capabilities slightly differently for the onset and success of negotiations. For studying the onset of negotiations over rivers, we measure the relative capabilities of the challenger state in the dyad, or the state that is initiating the river claim. We expect that this state's actions are likely to be more decisive in determining how the claim is 
managed; a much stronger challenger state should be much better able to prompt the onset of negotiations with a weaker adversary than a much weaker challenger state (which may be ignored by a much stronger adversary). Once negotiations start, though, we expect that what matters most is the overall balance of relative capabilities. Whether the challenger or target state is stronger should matter less than the extent to which one state is stronger than its opponent.

Hypothesis 5: States are more likely to begin negotiations over a river claim if the challenger state (the state initiating the claim) is more powerful than its adversary.

Hypothesis 5A: Negotiations over a river claim are more likely to be successful if there is a greater imbalance of relative capabilities than if both states are roughly equal.

A history of non-hostile relations and previous cooperation between states should increase the chances for cooperation. Previous cooperation is likely to ease the uncertainties that typically characterize interactions under anarchy and provide safer grounds for positive interaction. Furthermore, a more cooperative and generally closer overall relationship should also indicate that states' ideal solution points are likely to be closer together -- the friendlier the relationship, the less likely either is to make extravagant demands that entail grave losses for the other, so cooperation should be easier when the two sides' initial demands are relatively closer together.

This basic argument has already received some empirical support with respect to rivers. Hensel, Mitchell, and Sowers (2006) argue that the presence of institutions in a basin increase the chances of positive conflict management. Brochmann (2006) finds that a signed treaty increases the chances of later water-specific cooperation in a dyad, and at least under special conditions, may reduce later water conflicts. And also Conca et al. (2006) find that a history of prior cooperation in a basin is a significant determinant of whether a basin will reach a treaty and whether individual states will join it. This discussion suggests the following hypothesis:

Hypothesis 6: States are more likely to begin negotiations over a river claim, and these negotiations are more likely to be successful, when they share a more cooperative general relationship. 
While previous treaties and closer overall relationships may help to create a more cooperative and trustful relationship, previous interactions between the riparian states may also have the opposite effect. One particularly noteworthy example is militarized conflict. Even if past research suggests that armed conflict over rivers has been relatively rare for most of human history, when it does occur such conflict should make subsequent cooperation more difficult. A substantial literature on recurrent conflict and rivalry has shown the negative impact of conflict on future relations between the adversaries, and cooperation over rivers is an area where we expect to see this effect manifested. While the greater urgency posed by armed conflict over the issue should be more likely to bring the adversaries to the negotiating table -- either on their own initiative or through the action of third parties seeking to prevent escalation -- this should also make it much more difficult to trust the other side sufficiently to enable a mutually acceptable compromise solution.

Hypothesis 7: States are more likely to begin negotiations over a river claim, but these negotiations are less likely to be successful, when the two states have recently experienced militarized conflict over the river claim

Similarly, a history of failed negotiations should also reduce the effectiveness of efforts to settle disputed issues peacefully. We do not expect a significant impact of failed negotiations on the onset of future negotiations, as we do for a history of recent armed conflict over the issue. When negotiations do occur in the context of recent negotiation failures, though, we expect them to be less successful. A failed previous negotiation is an indication that this adversary cannot be trusted, which should decrease the chances of a successful outcome.

Hypothesis 8: Negotiations over a river claim are less likely to be successful when the two states have recently experienced unsuccessful negotiations over the claim.

\section{Research Design}

We test these hypotheses using the Issue Correlates of War (ICOW) project's data set on cross-border river claims (e.g. Hensel et al. 2008; Hensel and Brochmann 2009). This data set attempts to identify every case of explicit disagreement between two or more nation-states over 
the usage of a cross-border river, and currently covers the Americas, Western Europe, and the Middle East from 1900-2001.

\section{Dependent Variables}

Negotiation Onset

This variable is taken from the ICOW project's data on peaceful attempts to settle river claims. It is measured as a dummy variable, taking the value of one if at least one new round of negotiations began over the river claim in a given year, and zero otherwise. This includes any form of peaceful negotiations, ranging from strictly bilateral negotiations between the claimants to negotiations with the non-binding participation of third parties (as in good offices or mediation) or submission of the claim to a binding third party decision. For more details, see Hensel, et al. (2006).

\section{Negotiation Success}

We measure the success of a given round of negotiations by whether or not it ended in a treaty or agreement over the substance of the river issue. ${ }^{2}$ Producing such an agreement clearly indicates that the negotiations were more successful than they would have been had they ended without agreement. Further research might profitably investigate the aftermath of river agreements, as a given agreement may or may not be ratified (if necessary) and carried out by both sides, and may or may not end all contention over the river claim in question. Matters of ratification and compliance are conceptually distinct from the process of reaching an initial agreement, though, involving very different political processes in different states. Such processes lie beyond the scope of the present project, which focuses on the processes by which state leaders attempt to reach agreement in negotiations over river claims. In any case, most

\footnotetext{
${ }^{2}$ For the purposes of this paper's analyses, we are only considering agreements that covered the substance of the claim. This excludes what the ICOW project terms "functional" agreements, which involve essentially stopgap measures that may help to increase confidence between the adversaries but do not address the substance of the issue, as well as "procedural" agreements that typically involve an agreement to meet again for further talks in the future. To us, neither type of agreement indicates a successful round of negotiations over a river claim.
} 
agreements over river claims have been ratified (where needed) and carried out by both signatories. $^{3}$

\section{Independent Variables: The River}

\section{River Importance}

We conceptualize the importance of a given river in a number of ways. We begin with basin-level data on both water supply and water demands, which allows us to determine the amount of pressure on fresh water resources in the area; a river that flows through an area where water is scarcer or where demands are greater should be considered more important in the sense that we describe in this paper. The Transboundary Freshwater Dispute Database (TFDD) spatial data set at Oregon State University (TFDD 2008) includes two particularly useful basin-level measures of water supply: water discharge (the volume of water that flows through rivers in the basin) and water runoff (the amount of water -- whether from rain, snow melt, or other sources -that flows over the land surface) in each basin; each measure is log-transformed for our analyses. ${ }^{4}$ It should also be noted that the TFDD data that we employ is only available in snapshot form, with one observation per river basin; there is no time series equivalent that could come close to covering the century-long domain of this study. We thus use this data for the entire time period of the study, arguing that while imperfect, this approach is better than the alternative of excluding water scarcity variables from the analysis entirely. The TFDD also includes a number of possible basin-level measures of water demands, which offer a second way to measure the relative importance of different rivers (with rivers in areas experiencing higher water demands being considered more important). We use the average population density in the river basin (logged) to capture the impact of human settlement on water demands.

We also measure the importance of the river using the ICOW project's index of river claim salience (Hensel, Mitchell, and Sowers 2006; Hensel, et al. 2008). This index attempts to

\footnotetext{
${ }^{3}$ There have been 60 substantive agreements in negotiations over the river claims addressed in this paper. Of these, fully $70 \%$ have been both ratified and carried out by both parties; only nine (15\%) failed to achieve ratification in both governments and nine others $(15 \%)$ failed to be carried out by both sides.

${ }^{4}$ Where one or both sides of a given international river are governed as colonies or other dependencies of a foreign power, the water scarcity variables that are used reflect the value for the colony rather than the colonizer, because that is the area affected by the river in question. For example, the water supply and demand figures for France have very little impact on the demand for rivers shared by French Guiana and Brazil, although French Guiana's water supply and water demands likely have a significant impact. All other variables in our analyses (such as democracy and relative capabilities) reflect the colonial ruler, though, as this is the actor that is involved in any conflict or negotiations over the use of the river.
} 
measure the overall value of the river that is involved in the claim, based on six factors that are believed to make the river more valuable to one or both of the claimants: (1) river location in the state's homeland territory rather than in colonial or dependent territory, (2) navigational usage of the river, (3) level of population served by the river, (4) the presence of a fishing or other resource extraction industry on the river, (5) hydroelectric power generation along the river, and (6) irrigational usage of the river. Each factor contributes up to one point per state to the overall salience index, producing a dyadic measure that can range in principle from zero (for a river with essentially no measurable salience) to twelve. For more detail on the coding of salience see Hensel, et al. (2006, 2008).

\section{Current vs. Future Problems}

The ICOW river claims data set identifies the specific issues involved in each claim. These might include problems related to river quantity, river quality, or navigation. Furthermore, these might include current problems -- i.e., those where the contentious dam, irrigation or diversion project, pollution, or other root of the problem is already in effect -- and/or future problems, which are being protested before they actually take effect. We measure this with a dummy variable indicating whether the river claim exclusively involves future problems, such as a dam or diversion project that is under construction but not yet in operation. The alternative includes claims over problems that are currently in operation as well as claims that are partly over currently operating problems and partly over future problems; our expectation is that problems that are not currently causing any perceived harm to the challenger state will be handled differently from those that are already causing at least some harm.

\section{River Course}

The ICOW project categorizes the course of each river based on a number of major world atlases and geographic reference sources. ${ }^{5}$ This is measured with a dummy variable that indicates rivers that cross from one state's territory into another's from those that do not pass through at least one of the state's territory. Typical alternative river courses include rivers that form the border between the two states but only pass separately through one or neither state's

\footnotetext{
${ }^{5}$ These sources include the National Geographic Atlas of the World, 8th edition; Times Atlas of the World, 10th comprehensive edition; Hammond Concise World Atlas; Macmillan's Planet Earth Atlas; Merriam-Webster's Geographical Dictionary; and the Columbia Gazetteer of the World.
} 
territory, as well as tributaries that pass through one state's territory and then end by flowing into a separate river along the border.

\section{River Institutionalization}

The institutionalization of rivers is measured by the presence of previous river treaties between the two states in question, and is collected from the TFDD project. We focus on the subset of TFDD treaties that directly address river issues related to the three types of ICOW river claims mentioned above: treaties over the allocation of water quantities between two or more riparian states, treaties with specific water quality provisions, and treaties concerning navigation of international rivers. Because we are studying how a specific claim is managed, we are only interested in relevant treaties, which are those that cover the type of river issue(s) involved in the claim. Thus, for a river claim over water quantity, we code this as a dummy variable indicating whether or not these two states share at least one TFDD treaty that addresses water quantity issues on this river.

\section{Independent Variables: The Riparian States}

\section{Relative Capabilities}

We measure state capabilities with the Composite Index of National Capabilities (CINC) score from the Correlates of War (COW) project's National Material Capabilities data set, which ranges from zero to one and indicates the total percentage of the international system's capabilities held by the state in question during the year of observation (COW 2008). We use this CINC score to measure each riparian state's relative capabilities as the percentage of the total dyadic capabilities held by that state, by dividing that state's CINC score by the combined CINC scores of the two riparians being studied.

\section{General Context of Relations}

The general context of relations between two riparian states will be measured by two states' shared memberships in international organizations (IGOs). If two countries have many joint memberships, it is reasonable to assume that they share at least a minimum of common preferences and a history of cooperation, and that they are more likely to seek to cooperate in the future. IGOs provide a forum for information sharing and ease transaction costs of cooperation 
and we expect spill-over effects to other forms of cooperation. We measure joint memberships in IGOs by summing the number of IGO memberships shared by the two countries in a dyad based on the most updated IGO membership data described in Pevehouse, Nordstrom, and Warnke (2004). ${ }^{6}$ This variable covers a range of organizations from large multilateral bodies like the UN to highly specialized organizations like the Mekong River Commission.

\section{Recent Interactions over the River Claim}

We also examine the effect of two dimensions of recent interactions over the river claim: militarized conflict and unsuccessful negotiations. This conflict variable is originally based on the Correlates of War (COW) project's Militarized Interstate Dispute (MID) data set, which identifies every case where one nation-state threatens, displays, or uses military force against another (Ghosn, Palmer, and Bremer 2004). As we are only interested in militarized disputes that explicitly attempt to resolve river claims we use the ICOW project's restrictive coding of militarized disputes over each specific river claim, as described by Hensel, Mitchell, and Sowers (2006). Unsuccessful negotiations are those where the states failed to reach agreement, or where agreement was reached but at least one side failed to ratify or comply with the agreement. Both militarized conflict and failed negotiations over the issue should indicate to each side that the other is not trustworthy, suggesting that future cooperation should be difficult to achieve. These two variables following the coding scheme described by Hensel et al. (2008), which is a weighted scale whereby the impact of an event (whether militarized conflict or failed negotiation) is greatest effect in the first year after its occurrence and declines each year afterward, disappearing entirely after ten years.

\section{Control Variables}

Although we do not offer an explicit hypothesis, we control for the effects of joint democracy, which we expect (based on past research) to create an expectation of stability and an atmosphere where agreements are likely to be honored. Joint democracy is measured using the Polity IV data (Marshall, Jaggers, and Gurr 2008), in the form of a dummy variable indicating whether both riparian states are considered democratic (as measured by a value of seven or

\footnotetext{
${ }^{6}$ The dataset used to compile this variable records membership in 495 different IGOs of all kinds, dating back to 1815 (Pevehouse, Nordstrom and Warnke 2004).
} 
greater on the Polity index that subtracts a 10-point index of autocratic characteristics from a 10point index of institutionalized democracy).

We also control for the type of settlement technique being employed. Drawing from research such as Mitchell and Hensel (2007), we expect to find important differences in the effectiveness of different techniques, although in this paper we have not offered theoretical explanations that would justify treating this as a separate independent variable. In particular, past research leads us to expect that non-binding third party techniques such as good offices or mediation should be somewhat less effective than bilateral negotiations, while binding third party arbitration or adjudication should be much more effective.

\section{Empirical Analyses}

We begin with a brief description of the data. For the spatial-temporal domain covered by the current ICOW river claims data set, there have been a total of 82 dyadic river claims, ranging from disagreements over navigation on the San Juan River between Nicaragua and Costa Rica to numerous disagreements in the Jordan or Tigris-Euphrates river basins. Table 1 offers a brief descriptive analysis of negotiations over these river claims.

[Table 1 about here]

These 82 dyadic river claims have lasted for a total of 644 claim-years. The vast majority of these -- 536 of 644 , or $83.2 \%$-- have maintained the status quo, with no effort to negotiate over the substantive issues under contention. In 57 years $(8.9 \%)$, the parties engaged in at least one round of substantive negotiations that failed to produce agreement. In the remaining 51 years $(7.9 \%)$, the parties engaged in negotiations that produced at least one substantive agreement over the issues under contention. This paper seeks to differentiate between the latter two categories; of the 108 years in which negotiations were held, what accounts for the difference between the 51 years in which substantive agreements were reached and the 57 years in which negotiations failed?

We pursue the answer through a multivariate analysis of negotiations over river claims. Table 2 presents a Heckman selection model of negotiations over river claims, using the 
population of 644 claim-years mentioned above. ${ }^{7}$ The first stage of the model (the selection stage) investigates the conditions under which the claimants are most likely to begin substantive negotiations over their river claim. For cases in which such negotiations are begun, the second stage of the model (the outcome stage) investigates the conditions under which the negotiations are most likely to produce a substantive treaty or agreement. The Heckman model also allows us to investigate the extent to which there is a systematic correlation between the error terms in the two stages, which would be manifested in a "selection effect" whereby the process of beginning negotiations is systematically related to the process of negotiation success.

\section{[Table 2 about here]}

Three separate models are presented, differing only in the variable that is used to measure the importance of the claimed river to the claimants. Separating these models is important for several reasons. First, there are high correlations between these different measures (ranging from .70 to .99); while they are measuring different aspects of the importance of a river, these aspects are closely related to each other. Furthermore, several of these measures are not available for every river basin in the data set, so using separate equations allows us to study the impact of each measure on as many cases as possible.

The first thing to notice about these three models is that none of them shows evidence of a systematic selection effect. All three models have a statistically insignificant rho parameter ( $p<.23$ in Model I, $p<.53$ in Model II, and $p<.37$ in Model III). This is not especially surprising, since -- as we noted earlier -- there are likely to be very different processes at work in the decision to begin negotiations over an issue and the decision to reach a specific agreement with the adversary over that issue.

\section{Impact of River Characteristics}

Our first hypothesis suggested that states should be more likely to begin negotiations when the river is more important to them, but less likely to be able to reach a mutually satisfactory agreement. The results for this hypothesis are mixed. As expected, the more salient the river claim in question is considered to be the more likely is it that a negotiation starts, but contrary to our expectations more salient claims also more often have successful negotiations.

\footnotetext{
${ }^{7}$ Some of the observations do not appear in Table 2 due to missing data on one or more of the variables, mostly due to three variables: joint democracy (which is missing for 37 of the 644 cases), basin runoff (101 cases), and basin discharge (139 cases).
} 
Water availability, whether measured through supply or demand, does not appear to have a significant impact on the onset of negotiations, but lower supply of fresh water reduces the chances of a successful negotiation as expected. Interestingly, higher demand from population growth also increases the chance for a successful negotiation, which is the opposite of what we had expected to find. More research is needed to understand this apparent greater likelihood of reaching agreement in more difficult situations, but a good possibility is that freshwater issues such as these are simply more amenable to cooperation and less so to conflict than are other issues such as territory, as suggested by Wolf (1998).

A way to help interpret the results of our analyses is through the analysis of marginal effects. Table 3 presents the predicted probability of negotiation onset for each measure of river importance that is used in Table 2, as well as the predicted conditional probability of negotiation success in the second stage of the model given that negotiations began in the first stage. As these results are only substantively meaningful for statistically significant effects, we will only comment on those. Most notably, the results here show that the salience of a river claim has a considerable impact on negotiations. An increase from the minimum to the maximum value of river claim salience increases the probability that a negotiation will begin more than 32 times and the probability of successful negotiations almost doubles. The probability of successful negotiations also more than doubles when population pressure is at the maximum level compared to the minimum, and is more than halved when the availability of water is at the minimum level compared to the maximum.

\section{[Table 3 about here]}

Our second hypothesis suggested that negotiations over a challenger's future concerns about river usage are more likely to begin but less likely to succeed than negotiations over current issues. This hypothesis is generally supported by our data as the variable is positive and significant in two out of three models in stage one and has a negative and significant impact in all models in stage 2, indicating that negotiations over future claims are indeed more difficult to reach agreement on. As in Table 3, Table 4 presents the marginal probabilities for statistically significant effects, calculated from Model III of Table 2. The probability of a negotiation starting is almost $40 \%$ higher when the claim involves only future grievances, but the probability that these negotiations are successful is more than one-third lower for claims over future concerns compared to current issues. 
[Table 4 about here]

Hypothesis 3 suggested that the course of the river would have a considerable impact on the interaction process, more precisely that states would be more likely to enter into negotiations over these rivers. This does not seem to be the case. Throughout our models, cross-border rivers have a lower probability of being negotiated over than other rivers. Substantively, the probability is reduced by more than $20 \%$ if the river's course is cross-border compared to any other configuration. such as forming the border between two states or flowing into a border river but not spending time within the separate territory of each state.

We expected that states that share relevant river treaties would be more likely to enter into negotiations and more likely to succeed in those attempts as stated by Hypothesis 4. Surprisingly this does not seem to have an impact at all, as the treaty variable remains insignificant throughout our models.

\section{Impact of Riparian State Characteristics}

We now turn from details of the river and its environment to details of the riparian states themselves. Hypothesis 5 suggested that states are more likely to enter into negotiations when the claim challenger is the most powerful, and that negotiations are more likely to be successful when there is a greater capability disparity between the two (whichever is more powerful) than when they are roughly equal. This hypothesis is not supported. In stage one of the model, negotiation onset, the challenger's capabilities only has a significant impact in Model I, and the effect is negative -- indicating that a stronger challenger actually decreases the chance of a negotiation starting.

An overall cooperative relationship between the two countries measured through joint IGO memberships is suggested by Hypothesis 6 to increase the chances of negotiations beginning as well as them being successful. This receives some support. An increased number of shared IGO memberships increase the chance of starting negotiations over river disagreements according to Model I. It also increases the chances of successful negotiations in two out of three models in stage 2. Moving from the minimum value of shared memberships to the maximum increases the probability of a negotiation success over $50 \%$.

Focusing on previous conflicts in the river basin, Hypothesis 7 suggested that a previous water conflict would increase the chances that negotiations begin, but decrease the chances for 
success in these negotiations. The outcome of negotiations does not seem to be affected by conflict history though. But as expected a recent conflict increases the chance that a negotiation starts, in fact, the probability increases almost four times from the minimum to the maximum time since conflict in this weighted measure, so Hypothesis 7 is partly supported.

Finally, Hypothesis 8 suggested that recent failed negotiations over a claim would decrease the chance of a successful new negotiation, and this is supported in two out of three models. Previous failures actually reduce the chance of a current success more than 6 times with a move from the minimum to maximum value of this variable.

Our controls for regime type and type of settlement attempts suggests that although joint democracies are more likely than other states to enter into negotiations (the probability is almost double compared to other regime configurations), the outcome of these negotiations is not dependent upon the type of regime in power. As expected, though, binding third party attempts to settle disagreements have a probability of success that is about $1 / 3$ higher than bilateral disagreements and almost double the probability of success compared to non-binding activities.

All in all, several of our hypotheses received support to some degree: Water importance matters, river claim salience the most $(\mathrm{H} 1)$; future river claims are easier to enter into negotiation over, but harder to solve (H2); a general cooperative relationship increases the chances of negotiations and success (H6); previous conflicts increases the chances of negotiations (H7); and finally, negotiations are less likely to succeed if there is a history of failed negotiations (H8). Some of our Hypotheses were not supported, though: The course of the river does not seem to have an impact (H3), neither does existing treaties (H4) nor the relative power relation between the two states (H5).

\section{Discussion}

These preliminary results suggest that we have made a promising start toward identifying the factors that influence the success of negotiations over international rivers. First, the fact that none of these models produced a significant rho coefficient suggests that there is no meaningful selection effect at work; the factors that influence the decision to begin negotiations do not seem to be related systematically to the factors that influence the decision to reach agreement in these negotiations. Nevertheless many of the same factors that affect the decision to enter into negotiations also affect the outcome albeit somewhat differently. Still there may be reasons to 
believe that in addition to these general factors, when it comes to explaining the degree of negotiation success more specific factors such as the negotiation strategy employed, the identity of any third party or also domestic political factors in the two countries may play important roles.

But the results we have obtained through these analyses also offer important insights: First, the importance of a river matters for how negotiations evolve. The river claim salience index combines several aspects that are likely to increase the perceived importance of a river and our results here suggests that negotiations are more likely to begin and to succeed over more salient rivers. On the other hand, water scarcity -- measured by less supply of water reduced the chance of a successful agreement as expected. A river that is highly salient due to many different uses of the river, may be easier to reach agreements on as there will be more issues to bargain over and the opportunities to "give and take", and possibilities for issue linkage within the same river, will be greater. This can expand the bargaining range in a negotiation, contrary to a river where the main (or only) concern is a reduced flow of freshwater, and this may explain the differing impacts of these two variables on negotiation success.

Not surprisingly, future concerns over river usage are difficult to degree upon. Uncertainty among the parties regarding the other party's real plans for the river and also incentives to withhold information about own plans narrows the bargaining range, and there may also be in the interest of the target state to avoid reaching a decision as this will constrain future actions. Successful negotiations thus seem more likely in environments with a combination of a broad range of issues to bargain over combined with these issues being of current importance.

The fact that a previous treaty does not seem to help reach successful agreements is troubling. Is this because the parties have bad experiences with earlier treaties? Another possibility is that since a treaty already exists both parties expect more from new negotiations and that they thus are harder to agree on. Seen together with the results from a previous paper (Brochmann and Hensel 2009) where we found previous treaties to have a positive effect on the beginning of negotiations in general (meaning that we also included procedural and functional talks not just substantive talks to resolve a current issue as here), this suggests that previous treaties are less relevant when specific problems are addressed. This runs somewhat contrary to theoretical expectations of spill-over effects, but more generally spill-over effects seem to affect negotiation success: Even if specific river treaties do not increase the chances of successful negotiations, a generally cooperative relationship seem to do so. This is very much in line with 
institutionalist theory. Also in line with bargaining theory and our theoretical expectations is the fact that negotiations follow conflicts. And even more so, at least it does not seem that these negotiations are any harder to succeed in than other negotiations. Recent failed negotiations, on the other hand, makes the negotiations much more difficult. This may indicate that once negotiations have failed there is a need to involve other parties, as the negotiations with third party involvement are most likely to succeed.

Third parties may also be a possible solution to deal with especially problematic rivers, as our results, both from these analyses and earlier suggest that relations over cross-border rivers will be. River with this geographical configuration are less likely to be negotiated over than other rivers. This is not good news, especially not seen together with our previous finding (Hensel and Brochmann 2007) that these rivers have most claims. The scenario of the upstream/downstream configuration as the most conflict prone thus still holds. Rivers with other courses such as border rivers are probably much easier to negotiate over as each riparian will be affected by changes in water quantity and quality on the river in similar ways. This seems to be regardless of the relative power of the two riparians as these factors not appear to have much of an impact in our analyses.

Interestingly shared democracies do not have a higher success rate in their negotiations. They enter into more negotiations, though, and it may be that because of a mutual trust that prolonged negotiations will not have dramatic effect in such way of a conflict erupting, these negotiations are not more successful. Again, if we interpret this result in light of our previous finding (Brochmann and Hensel 2009), joint democracies seem to be more inclined than other states to enter into substantial negotiations, although they do not enter into more negotiations in general (see Brochmann and Hensel 2009).

\section{Conclusions and Implications}

In this study we have presented a simple model of negotiations over international rivers that emphasizes both characteristics of the rivers and their surrounding basins and characteristics of the countries sharing these rivers. This model suggests that factors that are specifically related to a disputed river as well as more general factors expected to affect the overall relationship between to river sharing states matter for how rivers are managed.

We have examined the model empirically using Heckman selection models, and have found that although there does not seem to be significant selection effects in place many of the 
same factors affect the two different stages in our analyses. River salience is the most decisive factor for negotiation onset but also recent conflicts over the river, the current dispute being over future concerns rather than present, a general cooperative relationship and both countries being democratic increases the chances for negotiations over ongoing claims. Whether or not the negotiations are successful is dependent on many of the same factors. Negotiations over highly salient claims are more likely to succeed than others and a general cooperative relationship increases the probability for success. Previous river specific cooperation does not have the expected positive effect, but failed attempts to cooperate hampers new attempts. Also the more binding a negotiations attempts to be, the more likely it is to succeed. And finally, the upstream/downstream scenario in rivers makes negotiations less likely to even start.

The results of this study suggest several implications for river policy. First, negotiations depend on several factors in the negotiation process, and seem most likely to succeed the more current and precise the negotiation is. While it might generally be expected that more difficult issues -- rivers that have more uses, and/or that flow through basins with high scarcity or high demands -- should be more difficult to resolve, this paper suggests that talks in such cases actually have a relatively high likelihood of success, so riparians should not be afraid to enter into such talks or to pursue a mutually beneficial solution. Third parties should also be involved in negotiations where the claimants themselves are unable to reach bilateral settlement, as this increases the chance for success -- which seems to be especially pressing over cross-border rivers, where river claims are more likely but negotiations less so.

These results do not offer the final word on negotiations over rivers, though. Future research could benefit greatly from further investigation of the effect and implementation of treaties. In this preliminary paper we have focused on the process of reaching agreement in negotiations over rivers, but this does not tell the complete story. It would also be useful to focus on individual rounds of negotiation, rather than taking the annual approach we have taken here, which has led to up to one-fourth of the negotiations to be aggregated together because of multiple rounds of talks being held in the same year. This approach was needed to allow us to use the selection model, because with one observation in the first stage of the model (studying whether or not negotiations were begun over a claim in a given year) we were limited to a single observation in the second stage (studying whether or not negotiations were successful during that year). As it turns out, though, there were no significant selection effects in any of these models, 
which suggests that in future work we can safely investigate the success of each individual round of negotiations with a standard logit or probit model. In any case, though, we believe that this study has made an important first cut at a very important problem in the management of international rivers.

\section{References}

Baxter, R. R. (1967) “The Indus Basin,” in A. H. Garretson, R.D. Hayton, and C.J. Olmstead, editors, The Law of International Drainage Basins. Dobbs Ferry, NY: Oceana Publications.

Brochmann, Marit (2006) "Conflict, Cooperation, and Management in International River Basins." Paper presented at the international workshop "Governance and the Global Water System," Bonn, Germany, 20-23 June

Brochmann, Marit and Paul R. Hensel (2009) "Peaceful Management of International River Claims" International Negotiations, forthcoming

Conca, K., F. Wu, and C. Mei (2006) 'Global Regime Formation or Complex Institution Building? The Principal Content of International River Agreements'. International Studies Quarterly 50(2): 263-285.

COW (2008) Correlates of War project web site. $<$ http://www.correlatesofwar.org $>$

Dinar, Shlomi (2008) International Water Treaties. Negotiation and cooperation along transboundary rivers. London and New York: Routledge

Dombrovsky, Ines (2007) Conflict, Cooperation and Institutions in International Water Management. An Economic Analysis. Cheltenham: Edward Elgar Publishing Ltd.

Elhance, Arun P. (2000) "Hydropolitics: Grounds for Despair, Reasons for Hope," International Negotiation 5: 201-222.

Fearon, James D. (1995) "Rationalist Explanations for War." International Organization 49, 3 : 379-414.

Giordano, Meredith A. \& Aaron T. Wolf (2003) 'Sharing Waters: Post-Rio International Water Management', Natural Resources Forum 27: 163-171.

Ghosn, Palmer and Ghosn, Faten, Glenn Palmer, and Stuart Bremer (2004). "The MID3 Data Set, 1993-2001: Procedures, Coding Rules, and Description." Conflict Management and Peace Science 21, 2 (Summer): 133-154. 
Hensel, Paul R., Sara McLaughlin Mitchell, and Thomas E. Sowers II (2006). "Conflict Management of Riparian Disputes", Political Geography 25, 4: 383-411.

Hensel, Paul R. and Marit Brochmann (2007) "Armed Conflict over International Rivers: The Onset and Militarization of River Claims." Paper presented at the Annual Meeting of the International Studies Association, Chicago.

Hensel, Paul R., Sara McLaughlin Mitchell, Thomas E. Sowers II, and Clayton L. Thyne (2008) "Bones of Contention: Comparing Territorial, Maritime, and River Issues." Journal of Conflict Resolution 52, 1: 117-143

Internationalwaterlaw.org (2009). Last updated 9 January 2008. $<\mathrm{http}$ :/www.internationalwaterlaw.org/intldocs/watercourse_status.html $>$.

Keohane, Robert O. (2002). Power and Governance in a Partially Globalized World. New York: Routledge.

Keohane, Robert O. and Elinor Ostrom (1994) "Introduction." Journal of Theoretical Politics 6(4): 403-428.

Lowi, Miriam R (1995) "Rivers of conflict, rivers of peace", Journal of International Affairs, 49(1): 123-145.

Lowi, Miriam R (1999) "Water and Conflict in the Middle East and South Asia: Are Environmental Issues and Security Issues Linked?", Journal of Environmental Development, 8(4): 376-396.

Mitchell and Hensel (2007) "International Institutions and Compliance with Agreements" American Journal of Political Science, 51(4): 721-737

Morrow, James D. (1994). "Modeling the Forms of International Cooperation: Distribution versus Information." International Organization 48 (3): 387-423.

Pevehouse, Jon, Timothy Nordstrom, and Kevin Warnke (2004). Intergovernmental Organizations, 1815-2000: A New Correlates of War Data Set. $\underline{\text { Accessed online at }}$ $\leq$ http://www.correlatesofwar.org $>$.

Reiter, Dan (2003): "Exploring the Bargaining Model of War" Perspectives on Politics, 1(1): $27-43$.

Song, Jennifer, and Dale Whittington (2004). "Why have some countries on international rivers been successful negotiating treaties? A global perspective." Water Resources Research 40, 5: W05S06, doi:10.1029/2003WR002536. 
Spector, Bertram. I. (2000). "Motivating Water Diplomacy: Finding the Situational Incentives to Negotiate." International Negotiation 5: 223-236.

Stein, Janice Gross, editor (1989). Getting to the Table. Baltimore: Johns Hopkins University Press.

TFDD (2008). Transboundary Freshwater Dispute Database web site. $<\mathrm{http}: / /$ www.transboundarywaters.orst.edu/database/>.

Wolf, Aaron T. (1998). "Conflict and Cooperation along International Waterways." Water Policy 1, 2: 251-265.

Zartman, I. William (1989). Ripe for Resolution, 2nd ed. New York: Oxford Press. 


\section{Table 1: Frequency of Negotiations over River Claims}

$\underline{\text { Peaceful Management of River Claim Observations }}$

No substantive negotiations $536(83.2 \%)$

Failed substantive negotiations $57(8.9 \%)$ (no agreement)

Successful substantive negotiations $51(7.9 \%)$ (agreement reached)

Total claim-years in data:

644 
Table 2: Accounting for the Onset and Success of Negotiations, 1900-2001

\begin{tabular}{|c|c|c|c|}
\hline & Model I & Model II & Model III \\
\hline Variable & Coefficient & Coefficient & Coefficient \\
\hline \multicolumn{4}{|c|}{ Outcome: Negotiation Success } \\
\hline $\log ($ basin runoff $)$ & $0.21(0.09)^{* * *}$ & --- & --- \\
\hline Log(pop. density in basin) & --- - & $0.22(0.13)^{* *}$ & --- \\
\hline River claim salience & --- & --- & $0.10(0.07)^{*}$ \\
\hline Claim only over future & $-1.01(0.33)^{* * *}$ & $-0.54(0.29)^{* *}$ & $-0.58(0.26)^{* *}$ \\
\hline Relevant river treaty & $-0.16(0.30)$ & $-0.30(0.27)$ & $-0.20(0.26)$ \\
\hline Stronger side capabilities & $0.61(1.28)$ & $2.11(1.51)^{*}$ & $-0.11(1.27)$ \\
\hline $\log ($ shared IGOs $)$ & $0.10(0.11)$ & $0.20(0.08) * * *$ & $0.14(0.08)^{* *}$ \\
\hline Recent armed conflict & $-0.29(0.25)$ & $0.03(0.29)$ & $-0.17(0.27)$ \\
\hline Recent failed negotiations & $-0.11(0.10)$ & $-0.18(0.10) * *$ & $-0.17(0.10)^{* *}$ \\
\hline Joint democracy & $-0.20(0.35)$ & $0.17(0.29)$ & $-0.09(0.31)$ \\
\hline 3rd party: Non-binding & $-0.41(0.30)^{*}$ & $-0.21(0.29)$ & $-0.17(0.27)$ \\
\hline 3rd party: Binding & $1.41(0.67)^{* *}$ & $0.93(0.74)$ & $1.06(0.71)^{*}$ \\
\hline Constant & $-0.93(1.56)$ & $-2.97(1.87)^{*}$ & $0.31(1.21)$ \\
\hline \multicolumn{4}{|l|}{ Selection: Negotiation Onset } \\
\hline $\log ($ basin runoff $)$ & $0.01(0.04)$ & --- & --- \\
\hline Log(pop. density in basin) & -- & $-.003(0.06)$ & 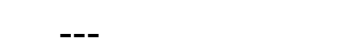 \\
\hline River claim salience & --- & -- & $0.09(0.03)^{* * *}$ \\
\hline Claim only over future & $0.22(0.16)^{*}$ & $0.08(0.14)$ & $0.21(0.15)^{*}$ \\
\hline Cross-border river & $-1.10(0.28)^{* * *}$ & $-1.03(0.28)^{* * *}$ & $-1.40(0.31)^{* * *}$ \\
\hline Relevant river treaty & $-0.09(0.16)$ & $-0.10(0.14)$ & $-0.14(0.14)$ \\
\hline Challenger capabilities & $-0.48(0.26)^{* *}$ & $-0.09(0.22)$ & $-0.19(0.20)$ \\
\hline Log(shared IGOs $)$ & $0.08(0.04)^{* *}$ & $0.03(0.03)$ & $0.02(0.04)$ \\
\hline Recent armed conflict & $0.35(0.17)^{* *}$ & $0.25(0.17)^{*}$ & $0.29(0.17)^{* *}$ \\
\hline Joint democracy & $0.22(0.21)$ & $0.42(0.16) * * *$ & $0.36(0.16)^{* *}$ \\
\hline Constant & $-0.20(0.43)$ & $-0.09(0.39)$ & $-0.25(0.30)$ \\
\hline Rho (S.E.): & $-0.67(0.37)$ & $0.40(0.56)$ & $-0.39(0.39)$ \\
\hline $\mathrm{X}^{2}:$ & $21.19(10 \mathrm{df}, \mathrm{p}<.02)$ & $13.65(10 \mathrm{df}, \mathrm{p}<.19)$ & $15.67(10 \mathrm{df}, \mathrm{p}<.11)$ \\
\hline N (2nd stage): & $509(84)$ & $606(107)$ & $606(107)$ \\
\hline
\end{tabular}

$* \mathrm{p}<.10, * * \mathrm{p}<.05, * * * \mathrm{p}<.01$ (one-tailed tests). Robust standard errors in parentheses. 
Table 3: Marginal Effects of River Importance on Negotiations

\begin{tabular}{lll} 
Variable/Value & $\begin{array}{l}\text { Probability of } \\
\text { Negotiation Onset }\end{array}$ & $\begin{array}{l}\text { Conditional Probability } \\
\text { of Negotiation Success }\end{array}$ \\
\hline $\begin{array}{l}\text { Water Availability (logged basin runoff) } \\
6.60 \text { (minimum) }\end{array}$ & .109 & .458 \\
10.03 (mean) & .114 & .794 \\
14.57 (maximum) & .122 & .978 \\
Water Availability (logged basin discharge) & & \\
0.69 (minimum) & .103 & .730 \\
4.04 (mean) & .094 & .901 \\
8.80 (maximum) & .084 & .986 \\
& & \\
Water Demands (logged population density in basin) & .355 \\
0.00 (minimum) & .141 & .675 \\
3.52 (mean) & .138 & .855 \\
6.08 (maximum) & .137 & \\
& & .416 \\
ICOW River Claim Salience & & .612 \\
2.00 (minimum) & .007 & .804 \\
5.69 (mean) & .127 &
\end{tabular}

\section{Notes}

- Predicted probabilities computed with the MFX command in STATA 9.2, based on the models reported in Table 2 (and one additional model for basin discharge that was not reported), with all other variables are held at their mean or modal values. 
Table 4: Marginal Effects of Statistically Significant Variables

\begin{tabular}{|c|c|c|}
\hline$\underline{\text { Variable/Value }}$ & $\begin{array}{l}\text { Probability of } \\
\text { Negotiation Onset }\end{array}$ & $\begin{array}{l}\text { Conditional Probability } \\
\text { of Negotiation Success }\end{array}$ \\
\hline \multicolumn{3}{|l|}{ Present vs. Future River Claims } \\
\hline Claim involves present grievance(s) & .127 & .613 \\
\hline Claim only involves future & .175 & .397 \\
\hline \multicolumn{3}{|l|}{ Cross-Border River } \\
\hline Other river course & .756 & -- \\
\hline Cross-border river course & .613 & -- \\
\hline \multicolumn{3}{|l|}{ Shared IGOs } \\
\hline 0.00 (minimum) & -- & .497 \\
\hline 1.85 (mean) & -- & .610 \\
\hline 4.55 (maximum) & -- & .759 \\
\hline \multicolumn{3}{|l|}{ Recent Conflict over Claim (weighted) } \\
\hline 0.00 (minimum) & .121 & -- \\
\hline 0.11 (mean) & .127 & -- \\
\hline 3.20 (maximum) & .399 & -- \\
\hline \multicolumn{3}{|c|}{ Recent Failed Negotiations over Claim (weighted) } \\
\hline 0.00 (minimum) & - & .658 \\
\hline 0.64 (mean) & -- & .615 \\
\hline 9.20 (maximum) & -- & .106 \\
\hline \multicolumn{3}{|l|}{ Joint Democracy } \\
\hline One or both not democratic & .127 & -- \\
\hline Both states democratic & .218 & -- \\
\hline \multicolumn{3}{|l|}{ Type of Settlement Attempt } \\
\hline Bilateral negotiations & -- & .614 \\
\hline Non-binding third party activities & -- & .543 \\
\hline Binding third party activities & -- & .923 \\
\hline
\end{tabular}

\section{Notes}

- Predicted probabilities computed with the MFX command in STATA 9.2, based on Model III from Table 2, with all other variables are held at their mean or modal values. 